incorporating the Pecha Kucha ${ }^{\mathrm{TM}}$ style of presentation utilizing 'short sharp bursts' of up to date paediatric teaching involving an evening of 6-7-minute presentations, occasionally with one longer presentation (10-20 minutes) on a wide range of topics. The sessions run for 90 minutes after afternoon handover to ensure optimal attendance.

Results Since the start of the programme 6 sessions have taken place and were well attended. Following each session, we obtained feedback via SurveyMonkey to allow us to refine and improve the evenings. Initially feedback showed that $79 \%$ rated it 'highly enjoyable' and $71 \%$ stated it was 'highly educational' but didn't like the longer presentation. As we continued to respond to feedback the ratings improved with $92 \%$ rating it 'excellent' but suggested that $8 \%$ still found the 'pace too fast'. General comments suggested further MDT involvement and with increased incorporation of this feedback has remained excellent.

Conclusions The evenings have been well received amongst attendees. Comments so far shows the Pecha Kucha ${ }^{\mathrm{TM}}$ style of presentation fosters a sociable atmosphere and positive learning environment. Constant feedback loops have allowed continual improvement with emphasis on ways to encourage not only MDT attendance but also MDT participation and presentation. Members of MDT and paediatric trainees all enjoyed the teaching and particularly commented on its 'informal and enjoyable atmosphere'. There is a wide scope for improving the format and content with a long list of healthcare professionals keen to take up the challenge of delivering a PED Talk.

\section{G191 PAEDIATRIC FREE OPEN ACCESS MEDICAL EDUCATION (FOAM) - BEHAVIOURS, TRENDS AND IMPLICATIONS}

1J Barton, ${ }^{2} \mathrm{~J}$ Round, ${ }^{3} \mathrm{~K}$ Knight. 'Student, St George's, University of London, London, UK; ${ }^{2}$ Paediatric Intensive Care Unit, St George's NHS Trust, London, UK; ${ }^{3}$ Paediatric Emergency Medicine, North Middlesex Hospital, London, UK

\subsection{6/archdischild-2020-rcpch. 161}

Introduction/Aims Free Open Access Meducation (FOAM) is a movement built around freely available (mostly online) medical education resources. Over the past decade its popularity has increased exponentially, to begin with primarily in critical care and emergency medicine, but more recently in paediatrics. However, little is known about FOAM users or their behaviours. This study aimed to investigate the user behaviours of one of the most popular paediatric FOAM websites.

Methods Using Google analytics for the website we explored user demographics and their patterns of behaviour. Descriptive statistics were used to identify early trends and highlight areas of potential future research.

Results 5,583 sessions were logged over four months in 2018/19. Users came from 146 countries, although the site is primarily written and promoted in the UK. $68.9 \%$ of users were female; most were 25-34 years; $57.3 \%$ used a mobile device, the remainder using desktop and tablet devices. Those using mobile devices spent less time using the website and were less likely to access the website via the homepage, instead landing on an article directed by an internet search. Fewer sessions were logged during the weekends than on weekdays.

Discussion FOAM is a rapidly developing form of medical education, demonstrated by large user numbers accessing this site which is just 2 years old. The site is being used by many beyond its intended readership and primarily being accessed from search engines. The behaviours of users suggest potential motivating factors for use, such as the need for timely, succinct information.

Google Analytics has the ability to provide rich and meaningful data. To date, the understanding of FOAM as a learning aid has not kept pace with its increasing popularity, we hope that this study encourages others to share their readily available data and contribute to our understanding.

Conclusions Google analytics can powerfully explore FOAM usage. Site curators should develop materials suitable for mobile or desktop usage, mindful also that their readership may well not be healthcare professionals. Given its popularity, further evaluation of user motivations and the effectiveness of FOAM should be prioritised.

\section{G192 SIMPROVISATION: A MODEL FOR STUDENT-LED SIMULATION}

1,2K Babla, 1,2J Lipton, 'S Chadha, 'B Uprety, 'G Bowden, 'S Williams, 'P Chopra, $1,2 \mathrm{~S}$ Thenabadu. 'Department of Postgraduate Medical and Dental Education, King's College Hospital NHS FT, London, UK; ${ }^{2}$ GKT School of Medical Education, King's College London, London, UK

\subsection{6/archdischild-2020-rcpch.162}

Introduction Simulation is well established in medical education, with scenarios designed by faculty to elicit specific learning outcomes. We describe and evaluate a learner-led style of simulation-based education that puts learners in control of the day.

Simprovisation harnesses the principles of socially-constructed learning and andragogy, encouraging learners to address their own learning requirements.

Participants are divided into two groups. They are asked to consider their learning needs and provided with resources and faculty support to write two simulation scenarios. Faculty remain available to guide scenario writing and offer 'microteaches' on required topics. The groups then swap and participate in the scenarios written for them by the opposite group. Each scenario is followed by a structured debrief, providing opportunities for participants to share their learning from scenarios.

Methods We delivered Simprovisation to 62 participants ranging from 4th year medical students to junior doctors. We conducted pre- and post-course questionnaire surveys and invited participants to focus groups to discuss their experiences.

Results Our feedback questionnaire shows $100 \%$ of 58 respondents found Simprovisation useful, and 95\% were able to meet at least 2 out of 3 self-determined learning outcomes.

Two focus groups conducted by $\mathrm{KB}$ were held in June 2018. Students were invited to focus groups at the study day, and later emailed reminder invitations. Semi-structured questions were used to explore the value and challenges of writing simulation scenarios, the simulation itself, and students' experience of the debrief, having written simulation scenarios. Thematic analysis transcriptions showed participants valued groupbased work and setting their own learning objectives. They found writing simulation scenarios to be challenging, but a valuable source of learning, and reported being more engaged compared to previous simulation study days. 
Discussion Simprovisation is an innovative style of simulationbased education that allows learners to effectively define and address their own learning needs. Placing the learner in control of the content of the study day is the principal difference between Simprovisation and standard models of simulation. We found that medical students were able to highlight and address learning needs that may not have been fully covered through our existing portfolio of simulation scenarios. We found learners used the opportunity to build on knowledge and share it with peers.

\section{G193 CAN ONLINE LEARNING RESOURCES OVERCOME THE CHALLENGES OF DISTANCE LEARNING FOR POSTGRADUATE TRAINEES IN PAEDIATRICS WITHOUT IMPACTING PERFORMANCE?}

${ }^{1} S$ Ogden, ${ }^{2} \mathrm{~S}$ Williams, ${ }^{2} \mathrm{~K}$ Barnes, ${ }^{1} \mathrm{C}$ Morgan. ${ }^{1}$ Neonatal Unit, Liverpool Women's Hospital, Liverpool, UK; ${ }^{2}$ Kid's Health Matters, Liverpool, UK

\subsection{6/archdischild-2020-rcpch. 163}

Background We have previously demonstrated that key components of the regional PGME paediatric teaching programme can be shared with the Advanced Clinical Practice (ACP) Paediatric MSc Programme. Both share archived material online and live streamed teaching sessions. This allows students geographically distant from the teaching location to access the MSc Programme. A recent survey of our paediatric trainees returning to training (RTT) revealed a similar need for accessing the regional training programme from more distant locations. We investigated whether the same learning outcomes can be achieved with remote online access by comparing how ACP trainees access the learning resources and their summative assessment results based on their distance from the teaching location.

Methods We stratified ACP trainees according to distance between workplace and teaching location with those in the upper quartile classified as distance learners. Using student's access data, we calculated the number and length of sessions accessed online. The amount of sessions where online resources were used instead of face to face teaching was compared between the distance learning group and the remaining trainees, alongside their mean exam performance across the MSc programme.

Results 77 trainees' data was analysed with a range in distance of $0-264$ miles from the teaching location (median 8.5 miles, IQR 0-28 miles). 475 hours of access data was analysed from all 4 modules of the course over 3 years. Distance learners attended more live streamed sessions online than those who lived closer (median $84 \%$ vs $32 \%$ $\mathrm{p}=0.00001$ ) yet the amount of archived material accessed was similar $(14.4$ vs $15.4 \mathrm{hr}, \mathrm{p}=0.9442)$. This suggests it is convenience rather than a predisposition that encourages students to choose online access methods. Despite this we did not demonstrate any difference between their summative exam result $(70 \%$ vs $67 \% \quad \mathrm{p}=0.169)$ or within individual modules, years or pathways.

Conclusion ACP MSc students prefer online methods of learning if they are based a greater distance from teaching locations and this does not impact their performance in summative assessments. This indicates paediatricians RTT with similar distance learning needs may also benefit from accessing online training opportunities in this way.
G194 STEP-UP TO CONSULTANT: INNOVATIVE SIMULATION PREPARING TRAINEES FOR THE CONSULTANT ROLE

R Winter, D Magnus. Bristol Medical Simulation Centre, Bristol Royal Hospital for Children, Bristol, UK

\subsection{6/archdischild-2020-rcpch. 164}

Background The transition from paediatric trainee to consultant has long been acknowledged as challenging. The RCPCH has implemented the START assessment and 'Stepping Up' programme to address this, but senior paediatric trainees remain apprehensive about their first consultant roles. When surveyed, they express particular concern about decisions trainees rarely get to practice, such as stopping CPR, managing junior colleagues and being on call from home.

Aims Design a simulation-based education programme to prepare general and subspecialty paediatric trainees for the consultant role.

Methods We conducted thematic analysis of trainee concerns from a 2017 RCPCH conference survey. These themes were developed into a framework of six domains which described different aspects of the consultant role: leader, educator, nurturer, juggler, negotiator and communicator. We designed challenging scenarios to test these domains, relevant to all trainees, and delivered two days of simulation-based education to 11 ST6-8 candidates. Given the high degree of difficulty, we recruited a specialist consultant-heavy faculty and took steps to protect candidates' psychological safety. Our programme included simulation innovations such as waking candidates with an overnight phone call, managing multiple clinical areas simultaneously and balancing clinical and non-clinical pressures.

Results 10 of 11 candidates gave us feedback, with 10/10 reporting they felt significantly more confident and competent to perform as consultants. 9/10 candidates felt simulation was superior to all other methods in preparing for difficult aspects of the consultant role. 6 candidates later approached us independently to report that they felt our course was more useful than the RCPCH START assessment.

Conclusions We have demonstrated that simulation is an effective tool to prepare senior trainees for transition to the consultant role. We intend to run this course on a regular basis for interested senior trainees across the UK.

\section{G195 WHO'S THE LEAD? CAN A NOVEL TOOL AND TARGETED SIMULATION TRAINING IMPROVE PAEDIATRIC EMERGENCY LEADERSHIP?}

R Cotton, J Woodruff, M Anton, P Hernandez, M Lane, A Narayanan, L Casanueva, M Burmester. Paediatric Intensive Care, Royal Brompton Hospital, London, UK

\subsection{6/archdischild-2020-rcpch. 165}

Aims To prospectively measure the impact of the Leadership In Medical Emergencies (LIME) course through objective measurements of self and team perception of leadership and teamwork.

Methods 7 paediatric practitioners attended a one-day LIME course which introduced Crisis Resource Management and a novel LEAD-A-Team tool (table 1) followed by 8 simulated emergencies. Modified-Concise Assessment of Leadership Management (CALM) score was prospectively recorded by the leader and an observer. CALM (Nadkarni et al.) was modified to better reflect LEAD-A-Team, resulting in a maximum score 